Annals of International Medical and Dental Research

E-ISSN: 2395-2822 | P-ISSN: 2395-2814

Vol-8, Issue-2 | March-April 2022

DOI: 10.53339/aimdr.2022.8.2.16

Page no- 113-119| Section- Research Article (Anesthesia)

\title{
A Comparative Study between Thoracic Epidural and Conventional Methods of Pain Management in Post Thoracotomy Patients
}

\author{
Rejaul Hasan ${ }^{*}$, Shawkat Mahmood ${ }^{2}$, Sayeda Begum Panna ${ }^{3}$, Md. Shamim Hossain Apel ${ }^{4}$, \\ Mohammad Zohanul Islam ${ }^{5}$
}

\begin{abstract}
${ }^{1}$ Assistant Professor, Department of Anesthesia, National Institute of Diseases of the Chest and Hospital (NIDCH), Mohakhali, Dhaka, Bangladesh.

Email ID: rajuhassan310@gmail.com

Orcid ID: 0000-0003-0370-7960.

2Junior Consultant, DNCC Dedicated COVID19 Hospital, Mohakhali, Dhaka, Bangladesh. Email ID: shawkatmahmoodsajib@gmail.com Orcid ID: 0000-0003-3481-1947

${ }^{3}$ Anaesthesiologist, Department of Anaesthesiology, National Institute of Disease of Chest and Hospital, Mohakhali, Dhaka, Bangladesh.

Email ID: saydabegum1985@gmail.com,

Orcid ID: 0000-0003-2595-5850

${ }^{4}$ Assistant Surgeon, Department of Anaesthesiology, National Institute of Disease of Chest and Hospital, Mohakhali, Dhaka, Bangladesh.

Email ID: shamim.uhl@gmail.com,

Orcid ID: 0000-0001-7328-5252

${ }^{5}$ Assistant Surgeon, Department of Anaesthesiology, National Institute of Disease of Chest and Hospital, Mohakhali, Dhaka, Bangladesh.

Email ID: zohanulislam@gmail.com,

Orcid ID: 0000-0001-6351-9297

*Corresponding author
\end{abstract}

Received: 16 November 2021

Revised: 08 January 2022

Accepted: 20 January 2022

Published: 18 February 2022

\section{Abstract}

Background: Postoperative discomfort has a negative impact on the outcome of thoracic surgical procedures, which are among the most painful operations. Controlling pain after a thoracotomy enhances patient satisfaction while lowering postoperative morbidity. Aim of the study: The aim of the study was to evaluate the effects of thoracic epidural and conventional pain management methods in postthoracotomy patients. Material \& Methods: A randomized crosssectional comparative study was conducted among 260 patients of post thoracotomy between January 2018 and December 2020 in a single tertiary-care hospital of Dhaka, Bangladesh. Outcomes of surgery were evaluated using the visual analogue score (VAS) at resting and coughing time. Results: We divided all 260 patients into two groups (group A: thoracic epidural 130; group B: conventional/control 130). The mean age of the patients was $49.74 \pm 23.46$ years in group $A$ and $50.48 \pm 56.23$ in group $B$. There were $61 \%$ male patients and $39 \%$ female patients, and the male: female ratio was 81:48 in group A, and 78:53 in group B. Mean duration of surgeries was $2.95 \pm 67.92$ hours and $2.84 \pm 57.31$ hours in group A and B respectively and mean follow up was 1.9 years and 1.4 years in group A and B respectively. The maximum number $(36.9 \% \%)$ of patients were in the age group of 50 to 54 years, and the minimum number $(4.61 \%)$ of patients were in the age group of 35 to 39 years. In group A, the maximum number (31) of patients had gone through open window formation, and a minimum number of patients (4) had gone through segmentectomy. And in group B, the maximum number (33) of patients had gone through open window formation, and a minimum number (4) had gone through hydatid cyst removal surgery. The change between comparative values of postoperative mean VAS scores at resting time and coughing time of both groups of patients was significant in this study. Conclusions: In thoracotomy surgery, the efficacy of thoracic epidural anesthesia is more evident than in other types of surgery. Although managing thoracotomy pain might be challenging, the advantages of proper pain management are substantial.

Keywords:- Thoracic Epidural, Pain Management, Thoracotomy. 
Annals of International Medical and Dental Research

E-ISSN: 2395-2822 | P-ISSN: 2395-2814

Vol-8, Issue-2 | March-April 2022

DOI: 10.53339/aimdr.2022.8.2.16

Page no- 113-119| Section- Research Article (Anesthesia)

\section{INTRODUCTION}

Post thoracotomy is frequently required for surgical treatment of thoracic diseases. One of the most painful acute postoperative operations is a thoracotomy. ${ }^{[1]}$ The discomfort associated with a thoracotomy is known as post-thoracotomy pain syndrome (PTPS). Pain that recurs or continues along a thoracotomy incision for at least 2 months after a surgical operation, according to the International Association for the Study of Pain. [2] One of the most significant influences on a patient's morbidity is postoperative pain. Acute pain might cause respiratory and cardiovascular problems after these treatments. $[3,4]$ Patients with insufficient analgesia may have difficulty coughing and clearing secretions following thoracotomy. This ailment may cause a longer stay in the hospital and a higher expense by delaying discharge. As a result, several analgesic treatments such as thoracic epidural analgesia (TEA), paravertebral blocks, and systemic analgesics can be applied. The gold standard is frequently referred to as TEA.[5] In post-thoracotomy pain, TEA was shown to be more effective than traditional analgesic models. 6,7$]$ Planned TEA reduces postoperative morbidity and mortality by giving adequate analgesia without causing respiratory compromise. [8] For postoperative thoracotomy pain control, epidural analgesia has become the preferred analgesic method. Not only does the procedure provide good pain relief, but it also avoids much of the sedation that systemic opiates cause. The epidural catheter also allows postoperative dosing and avoids much of the motor inhibition associated with intrathecal drug administration. To offer adequate pain management, substantially smaller quantities of medication delivered in the epidural region are required compared to systemic delivery. Epidural analgesia is utilized as much as possible in many therapeutic contexts, while systemic analgesia is used only when epidural analgesia fails or is contraindicated. [5,6] However, whether or not epidural analgesia should be utilized routinely for all thoracotomy patients, as well as where the catheter should be inserted, remains a point of contention. [8,9] Patients who get epidural analgesia experience less pain, are extubated sooner and have fewer pulmonary problems after surgery than patients who receive systemic opioids.[10] Although most anesthesiologists and thoracic surgeons believe that epidural catheters are safe and effective, there is a lot of disagreement over the degree and time of insertion, the drugs utilized, and whether or not supplement therapy should be employed. A thoracic epidural is an excellent pain treatment, despite the possible hazards and increased technical difficulties. This study aims to determine whether the effects of thoracic epidural are superior to conventional pain management methods in postthoracotomy patients.

\section{Objective}

The objective of the study was to evaluate the effects of thoracic epidural and conventional pain management methods in postthoracotomy patients.

\section{MATERIAL AND METHODS}

A total of 260 randomly selected patients were included in the study. We obtained the medical records and compiled data of the patients admitted to the hospital. All data was received 
Annals of International Medical and Dental Research

E-ISSN: 2395-2822 | P-ISSN: 2395-2814

Vol-8, Issue-2 | March-April 2022

DOI: 10.53339/aimdr.2022.8.2.16

Page no- 113-119 | Section- Research Article (Anesthesia)

through the complete consent of the patients and the hospital.

\begin{tabular}{|l|l|}
\hline Type of study & Prospective cross-sectional study \\
\hline Place of study & A single tertiary-care institution \\
\hline Study period & January 2018 to December 2020 \\
\hline $\begin{array}{l}\text { Study } \\
\text { population }\end{array}$ & $\begin{array}{l}260 \text { patients were included in the } \\
\text { study }\end{array}$ \\
\hline
\end{tabular}

\section{Statistical analysis}

Collected data were analyzed by SPSS (Statistical Program for scientific study) version 25.0 statistical package. P-value $<0.05$ was considered significant in our study.

\section{RESULTS}

[Table 1] showed the characteristics of the patients. It showed the mean age of the patients was $49.74 \pm 23.46$ years in group $A$ and $50.48 \pm 56.23$ in group $B$. The male: female ratio was 81:48 in group A and 78:53 in group B. Mean duration of surgeries was $2.95 \pm 67.92$ hours and 2.84 \pm 57.31 hours in group A and B, respectively. In addition, the mean follow-up was 1.9 years and 1.4 years in groups A and B, respectively. See table 1 below.

In [Table 2] the age group distribution of the patients is shown. In this study, the maximum number $(36.92 \% \%)$ of patients were in the age group of 50 to 54 years, and the minimum number $(4.62 \%)$ of patients were in the age group of 35 to 39 years. See table 2 below.
[Figure 1] showed the gender distribution of the patients in our study. There were $61 \%$ male patients and $39 \%$ female patients in this study. See figure I:

[Figure 2] showed the types of surgical procedures performed in both groups of patients. In group $\mathrm{A}$, the maximum number (31) of patients had gone through open window formation, and a minimum number (4) had gone through segmentectomy. And in group B, the maximum number (33) of patients had gone through open window formation, and a minimum number of patients (4) had gone through hydatid cyst removal surgery. See figure 2 below.

[Table 3] showed the preoperative mean VAS scores at the resting time of both groups of patients in this study. The VAS scores improved well by the 1st hour to 24th hour in the following measurements. See the comparative values of both groups in table 3 below.

Moreover, [Table 4] showed the postoperative mean VAS scores at coughing time of both group of patients in this study. The VAS scores also improved by the 1st hour to 24th hour in the following measurements. See the comparative values of both groups in table 4 below.

Table 1: Characteristics of the patients.

\begin{tabular}{|l|l|l|}
\hline Characteristics & Group A & Group B \\
\hline Mean age (years) & $49.74 \pm 23.46$ & $50.48 \pm 56.23$ \\
\hline Sex (Male: Female) & $81: 48$ & $78: 53$ \\
\hline Mean duration of surgery (hours) & $2.95 \pm 67.92$ & $2.84 \pm 57.31$ \\
\hline Mean follow-up & 1.9 years & 1.4 years \\
\hline
\end{tabular}


Annals of International Medical and Dental Research

E-ISSN: 2395-2822 | P-ISSN: 2395-2814

Vol-8, Issue-2 | March-April 2022

DOI: 10.53339/aimdr.2022.8.2.16

Page no- 113-119| Section- Research Article (Anesthesia)

Table 2: Age group of the patients (N-260).

\begin{tabular}{|l|l|l|}
\hline Age group (in years) & Frequency $(\mathbf{n})$ & Percentage (\%) \\
\hline $35-39$ yrs. & 12 & $4.62 \%$ \\
\hline $40-44$ yrs. & 19 & $7.31 \%$ \\
\hline $45-49$ yrs. & 63 & $24.23 \%$ \\
\hline $50-54$ yrs. & 96 & $36.92 \%$ \\
\hline $55-59$ yrs. & 42 & $16.15 \%$ \\
\hline $60-65$ yrs. & 28 & $10.77 \%$ \\
\hline
\end{tabular}

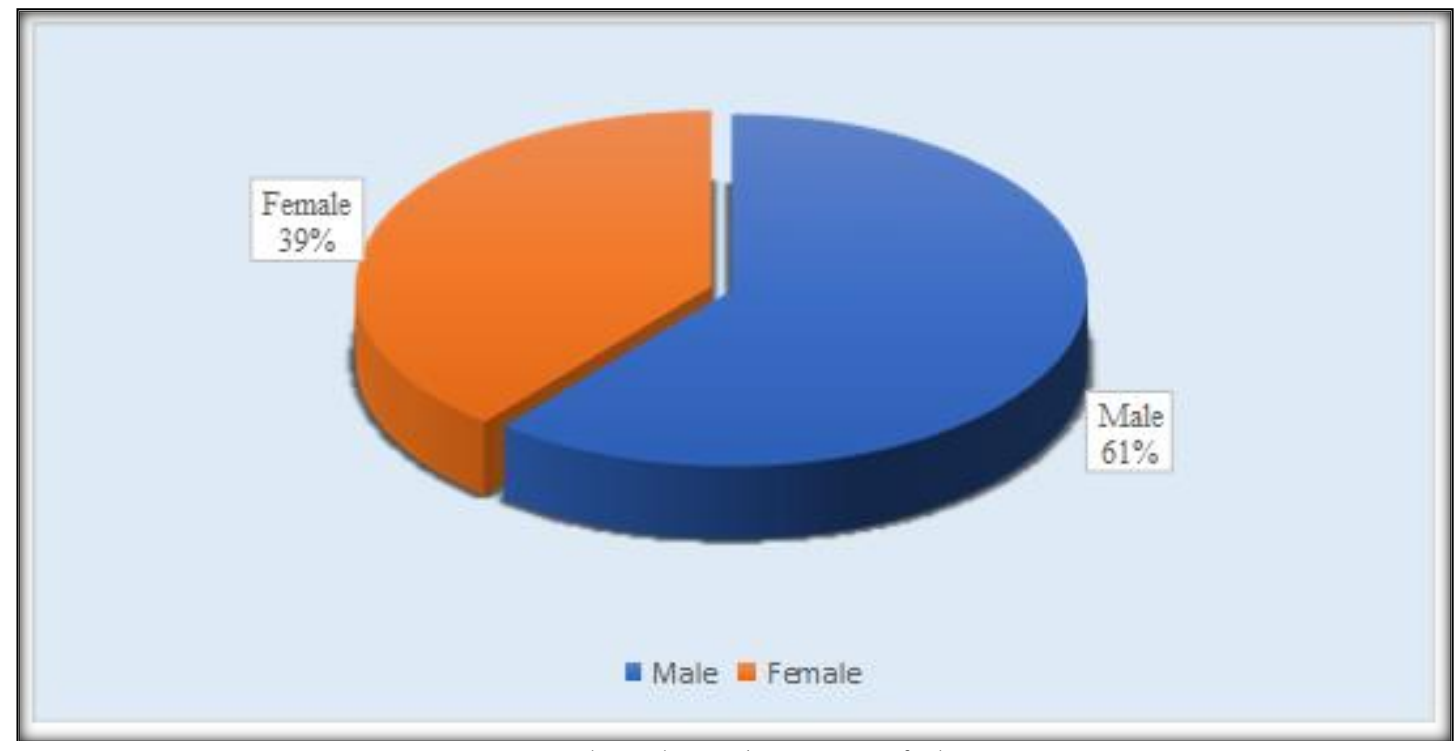

Figure 1: Gender distribution of the patients.

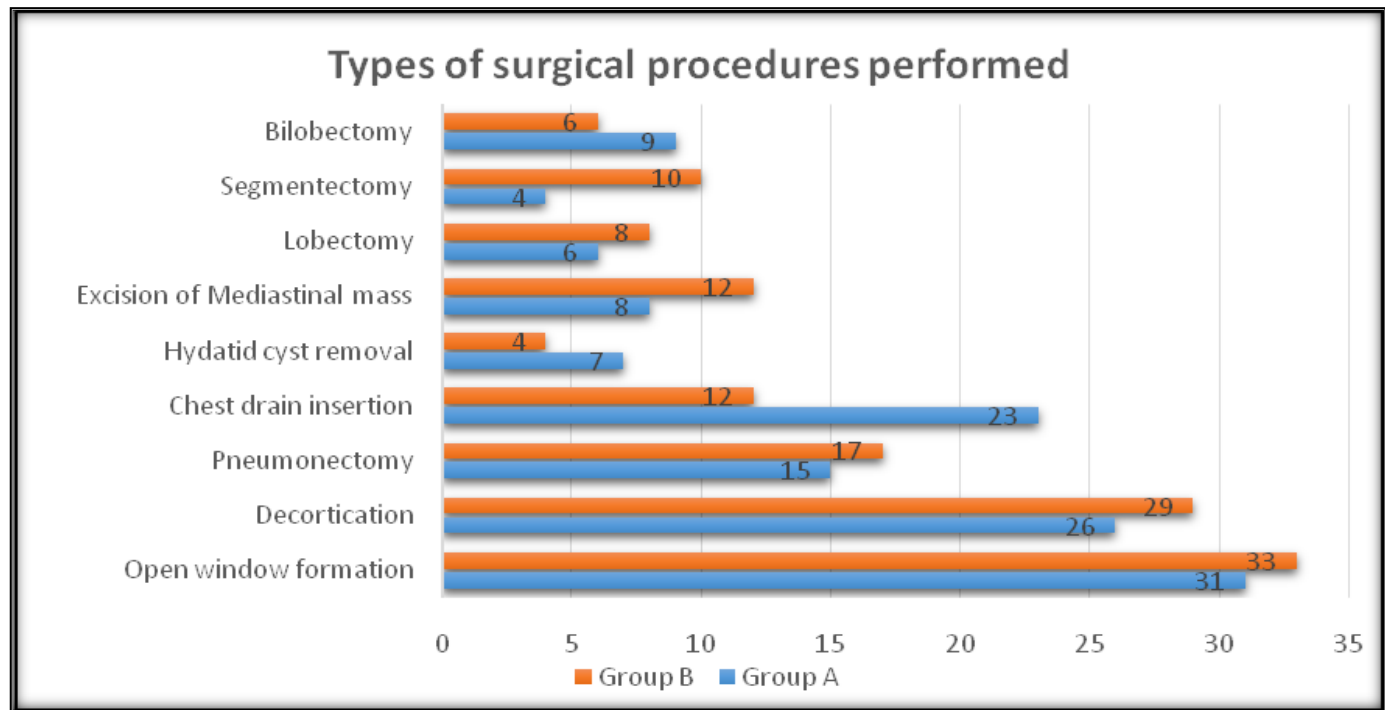

Figure 2: Type of surgical procedure performed in both groups of patients. 
Annals of International Medical and Dental Research

E-ISSN: 2395-2822 | P-ISSN: 2395-2814

Vol-8, Issue-2 | March-April 2022

DOI: 10.53339/aimdr.2022.8.2.16

Page no- 113-119| Section- Research Article (Anesthesia)

Table 3: Preoperative VAS comparison ( $\mathrm{N}=260)$.

\begin{tabular}{|l|l|l|l|}
\hline Preoperative VAS & Group A & Group B & P-Value \\
\hline Preoperative 1st hour & $1.97 \pm 6.33$ & $3.68 \pm 0.65$ & 0.041 \\
\hline Preoperative 2nd hour & $1.33 \pm 1.67$ & $3.31 \pm 1.39$ & 0.032 \\
\hline Preoperative 4th hour & $1.35 \pm 6.21$ & $2.98 \pm 6.41$ & 0.203 \\
\hline Preoperative 6th hour & $1.23 \pm 5.13$ & $2.16 \pm 6.21$ & 0.041 \\
\hline Preoperative 12th hour & $0.81 \pm 1.52$ & $1.62 \pm 2.21$ & 0.091 \\
\hline Preoperative 24th hour & $0.41 \pm 1.79$ & $0.84 \pm 1.54$ & 0.146 \\
\hline
\end{tabular}

Table 4: Preoperative and postoperative VAS comparison.

\begin{tabular}{|l|l|l|l|}
\hline Postoperative VAS & Group A & Group B & P-Value \\
\hline Postoperative 1st hour & $3.14 \pm 1.25$ & $3.89 \pm 0.47$ & 0.003 \\
\hline Postoperative 2nd hour & $2.33 \pm 2.71$ & $3.81 \pm 1.78$ & 0.005 \\
\hline Postoperative 4th hour & $2.15 \pm 1.83$ & $3.18 \pm 2.71$ & 0.007 \\
\hline Postoperative 6th hour & $2.13 \pm 2.03$ & $2.24 \pm 3.31$ & 0.152 \\
\hline Postoperative 12th hour & $1.51 \pm 1.61$ & $2.12 \pm 0.23$ & 0.257 \\
\hline Postoperative 24th hour & $1.09 \pm 2.01$ & $1.54 \pm 1.72$ & 0.103 \\
\hline
\end{tabular}

\section{DISCUSSION}

Pain is the most common postoperative complication in thoracic surgery patients.[6] Inadequate analgesia or opioids, cough, and respiratory center in thoracotomy patients have necessitated the use of different forms of analgesics. Many surgical treatments fail to manage pain appropriately.[7] Acute postoperative pain can harm multiple organ systems, including cardiovascular stress, autonomic hyperactivity, tissue breakdown (production of a catabolic state with suppression of anabolic hormones), increased metabolic rate, pulmonary dysfunction (most common after upper abdominal and thoracic surgery), increased blood clotting (hypercoagulability), fluid retention, immune system dysfunction, and delayed bowel function (ileus).[] When given before surgical stimuli, epidural, intravenous, and intramuscular opioids have been proven to lessen the degree of postoperative pain. [9]
According to one of these investigations, patients receiving pre-emptive epidural analgesia had considerably lower VAS pain levels and morphine needs.[9] Pre-emptive analgesia, on the other hand, has failed to reduce postoperative analgesic intake, according to some writers.[8] Several studies have employed the pre-emptive impact of TEA to reduce post-thoracotomy pain, $[6,7]$ but only one has demonstrated that pre-emptive thoracic analgesia reduced pain intensity for 2 or 3 days. In contrast, other studies have indicated that epidural anesthesia did not affect post-thoracotomy discomfort. In postthoracotomy pain, Neustein et al.10] found that pre-emptive epidural analgesia decreased maximum pain scores in the first 6 hours after surgery. However, they found no significant difference in pain levels after the first 6 hours. Our investigation discovered that preoperative epidural analgesia resulted in reduced maximum pain levels in the first 6 hours, 
Annals of International Medical and Dental Research

E-ISSN: 2395-2822 | P-ISSN: 2395-2814

Vol-8, Issue-2 | March-April 2022

DOI: 10.53339/aimdr.2022.8.2.16

Page no- 113-119 | Section- Research Article (Anesthesia)

similar to Neustein's study and that this drop lasted for 12 hours in the epidural analgesia group. In addition, for post-thoracotomy pain, epidural start offered superior analgesia than postoperative application. Preincisional initiation resulted in decreased pain scores at rest and coughing, especially in the early postoperative period. Previous research has been done to see if preemptive analgesia is beneficial. Preemptive epidural analgesia is more successful in thoracotomy surgery than in other surgical procedures, according to Bong et al.[1] In thoracic surgery, Yegin et al.[11] looked into the effectiveness of pre-and postoperative epidural analgesia against postoperative epidural analgesia. The intervention group received a bolus of bupivacaine and fentanyl before surgery. At rest and coughing, their patient's VAS score was relatively high (VAS $>3$ in the early postoperative period). Neustein et al.[10] studied bupivacaine-induced TEA before and after surgery. They discovered that preemptive TEA offered superior analgesia until the $6^{\text {th }}$ hour following surgery, with VAS rating

\section{REFERENCES}

1. Bong CL, Samuel M, Ng JM, Ip-Yam C. Effects of preemptive epidural analgesia on post-thoracotomy pain. J Cardiothorac Vasc Anesth. 2005;19(6):786-93. doi: 10.1053/j.jvca.2005.08.012.

2. Demmy TL, Plante AJ, Nwogu CE, Takita H, Anderson TM. Discharge independence with minimally invasive lobectomy. Am J Surg. 2004;188(6):698-702.

doi: 10.1016/j.amjsurg.2004.08.058.

3. McGovern I, Walker C, Cox F. Pain relief after thoracotomy. Br J Anaesth. 2007;98(6):844. doi: 10.1093/bja/aem112. inconsequential after that time. We found similar results. However, their VAS scores were more significant than ours in both the pre-and postoperative initiation groups. Our findings encourage us to employ preemptive TEA to give enough analgesia after thoracotomy, but our study had several limitations. We only keep track of VAS scores until the 24th hour after surgery. This study could have been more powerful if we had examined it over a more extended period.

\section{CONCLUSIONS}

After thoracotomy surgery, thoracic epidural surgery may provide better analgesia than other types of surgery. To decrease postoperative pain and morbidity and improve patient satisfaction, proper patient preparation and a thorough team approach to pain management involving the surgeon and anesthesiologist are critical. More research with large sample size is needed to show that epidural analgesia provides greater analgesia with fewer side effects and improved stress response results.

4. Groban L, Dolinski SY, Zvara DA, Oaks T. Thoracic epidural analgesia: its role in postthoracotomy atrial arrhythmias. J Cardiothorac Vasc Anesth. 2000;14(6):662-5. doi: 10.1053/jcan.2000.18318.

5. $\mathrm{Ng} \mathrm{A}$, Swanevelder J. Pain relief after thoracotomy: is epidural analgesia the optimal technique? $\mathrm{Br}$ Anaesth. 2007;98(2):159-62. doi: 10.1093/bja/ael360.

6. Kotzé A, Hinton W, Crabbe DC, Carrigan BJ. Audit of epidural analgesia in children undergoing thoracotomy for decortication of empyema. $\mathrm{Br} J$ Anaesth. 2007;98(5):662-6. doi: 10.1093/bja/aem065.

7. Salomäki TE, Laitinen JO, Nuutinen LS. A randomized double-blind comparison of epidural versus intravenous fentanyl infusion for analgesia 
Annals of International Medical and Dental Research

E-ISSN: 2395-2822 | P-ISSN: 2395-2814

Vol-8, Issue-2 | March-April 2022

DOI: 10.53339/aimdr.2022.8.2.16

Page no- 113-119| Section- Research Article (Anesthesia)

after thoracotomy. Anesthesiology. 1991;75(5):790-5. doi: 10.1097/00000542-199111000-00010.

8. Groban L. Central nervous system and cardiac effects from long-acting amide local anesthetic toxicity in the intact animal model. Reg Anesth Pain Med. 2003;28(1):3-11. doi: 10.1053/rapm.2003.50014.

9. Dahl JB, Kehlet $H$. The value of pre-emptive analgesia in the treatment of postoperative pain. Br J Anaesth. 1993;70(4):434-9. doi: 10.1093/bja/70.4.434.

10. Neustein SM, Kreitzer JM, Krellenstein D, Reich DL, Rapaport E, Cohen E. Preemptive epidural analgesia for thoracic surgery. Mt Sinai J Med. 2002;69(12):101-4.

11. Yegin A, Erdogan A, Kayacan N, Karsli B. Early postoperative pain management after thoracic surgery; pre- and postoperative versus postoperative epidural analgesia: a randomised study. Eur J Cardiothorac Surg. 2003;24(3):420-4. doi: 10.1016/s1010-7940(03)00345-2.

Source of Support: Nil, Conflict of Interest: None declared 